\title{
Intravenous disodium etidronate therapy in spinal cord injury patients with heterotopic ossification
}

\author{
K Banovac, ${ }^{1}$ F Gonzalez, ${ }^{1}$ Nancy Wade, ${ }^{2}$ J J Bowker ${ }^{1}$ \\ ${ }^{1}$ Department of Orthopaedics and Rehabilitation, University of Miami School of \\ Medicine, PO Box 016960, Miami, Florida 33101, USA; ${ }^{2}$ Jackson Memorial Medical \\ Centre, Miami, Florida, USA.
}

The goal of the present study was to use intravenous etidronate in the acute phase of heterotopic ossification (HO) in an attempt to achieve a high initial drug concentration at the site of the active ectopic ossification. The study included 27 consecutive patients with an acute onset of $\mathrm{HO}$ after spinal cord injury (SCI). The three-phase bone scan was used to confirm clinical diagnosis of HO. Disodium etidronate (Didronel) $300 \mathrm{mg}$ was administered intravenously daily for 3 to 5 days. In 20 patients there was a rapid (1-2 days) decrease of soft tissue swelling $(p<0.01)$ with no side effects associated with the intravenous administration. In seven patients there was minimal or no improvement of edema after intravenous etidronate. In these patients deep vein thrombosis was found in the affected limbs.

The effect of high dose etidronate on HO was determined in the group of 13 patients with positive clinical and scintigraphic finding of an acute $\mathrm{HO}$, but negative radiographic studies. After intravenous administration of etidronate for 3 days $(300 \mathrm{mg} /$ day) the drug was continued orally with $20 \mathrm{mg} / \mathrm{kg} / \mathrm{day}$ for 6 months. A placebo was not used in this study. In eight patients there was no radiographic evidence of $\mathrm{HO}$ after therapy while two patients had minimal ossifications. In three patients therapy was interrupted and all developed $\mathrm{HO}$ in 1-2 months.

Keywords: heterotopic ossification; paraplegia; spinal cord injury; bisphosphonate.

\section{Introduction}

Heterotopic ossification ( $\mathrm{HO})$ is a frequent complication after spinal cord injury (SCI) which may represent a significant problem in the rehabilitation process. The incidence of $\mathrm{HO}$ varies from $10 \%$ to $53 \%$ depending on the method of diagnosis. ${ }^{1-3}$ The pathogenesis of $\mathrm{HO}$ remains uncertain and the diagnosis is based on radiographic and scintigraphic tests. To date, there is no satisfactory medication for this problem. The recommended prevention of $\mathrm{HO}$ with bisphosphonates is not generally accepted, although Stover and coworkers reported a decrease prevalence of $\mathrm{HO}$ in patients treated prophylactically with etidronate after SCI. ${ }^{4,5}$ These authors also found that patients taking prophylactic etidronate developed a significantly smaller amount of
$\mathrm{HO}$ than the patients taking placebo. ${ }^{4} \mathrm{Al}-$ though there is a well documented beneficial effect of etidronate on the development of $\mathrm{HO}$, still there are significant differences in the individual responses to medication. The differences in therapeutic response can in part be due to the physicochemical characteristics of the drug. Because of low solubility in water, the reabsorption of bisphosphonates in the intestinal tract fluctuates from $1 \%$ to $10 \% .{ }^{6.7}$ To avoid these variations and to improve bioavailability of etidronate, in this study etidronate was initially administered parenterally and then continued orally with a higher dose ${ }^{8,9}$ than presently recommended. ${ }^{10}$ Similar doses of etidronate have been recently introduced in the therapy of hypercalcemia of malignancy. ${ }^{11-1}$ 


\section{Methods}

\section{Patients}

The patients involved in the study were admitted to the rehabilitation center 2-6 weeks (3.6 \pm 1.1 weeks; mean $\pm \mathrm{SD})$ after SCI. We studied nonselected patients with $\mathrm{HO}$ (two female and 25 male), ranging in age from 16 to $54(36 \pm 6$, mean \pm SD $)$ years. Quadriplegia was diagnosed in 15 patients (nine complete and six incomplete, Frankel class A) and 12 had paraplegia (11 complete and one incomplete Frankel class B). The diagnosis of $\mathrm{HO}$ was based on the presence of clinical symptoms (acute swelling, reduction of range of motion and increased body temperature), laboratory tests (increased serum alkaline phosphatase and accelerated erythrocyte sedimentation rate), radiographic studies and bone scintigraphy. Three-phase bone scintigram was obtained using technetium $99 \mathrm{~m}$ labeled methyl-bisphosphonate. We used scintigraphic criteria for the diagnosis of $\mathrm{HO}$ recommended by Freed et al. ${ }^{18}$ The intravenous therapy was started in patients with the earliest positive findings (phase 1 and 2). Prior to therapy radiographic studies and a venogram were obtained in all patients.

\section{Administration of etidronate}

Etidronate disodium (Didronel, Norwich Eaton Pharmaceuticals, Inc, Norwich, NY) was administered in a dose of $300 \mathrm{mg}$ intravenously over a period of 3 hours. ${ }^{11.14 .16}$ An infusion was given in the afternoon from $5 \mathrm{pm}$ to $8 \mathrm{pm}$ to avoid interference with the daily rehabilitation program. During intravenous therapy, patients had an indwelling catheter to prevent bladder distension and were encouraged to drink fluid (2-31 daily). Intravenous etidronate was given for 3 days in 24 patients and 5 days in the remaining three patients. After parenteral therapy, etidronate was administered orally $20 \mathrm{mg}$ / $\mathrm{kg}$ /day for 6 months. ${ }^{9}$ Radiographic evaluation was performed every 2 months for the first 6 months and then every 6 months.

Quantitative analysis of soft tissue swelling For quantitative analysis the circumferences of the thigh and ectopic bone mass were measured. The effect of etidronate on soft tissue swelling was determined by the measurement of thigh circumference $10^{\prime \prime}$ above the superior pole of the patella at full knee extension $\left(0^{\circ}\right)$. The measurements were done in bed, in the morning, daily for the first 5 days and then every week. The differences in circumference were expressed in centimeters and used in statistical analysis.

\section{Quantitative analysis of heterotopic ossification}

Quantitative assessment of ectopic bone was determined by planimetry on the radiographs obtained at least 6 months after intravenous therapy. This part of the study included 24 patients who completed 6 months of therapy. The area of bone mass was measured on anteroposterior view by a compensating polar planimeter 62002 (Keuffeal \& Esser, Germany). Two measurements were obtained by two observers (FG and $\mathrm{KB}$ ) and the mean value of the measurements was used for statistical evaluation. The variation between the measurements was less than $1 \%$. In addition the ectopic mass was determined in a group of 11 SCI patients previously treated with oral etidronate alone. In this group, patients were treated initially with $20 \mathrm{mg} / \mathrm{kg} /$ day for 2 weeks, followed by $10 \mathrm{mg} / \mathrm{kg} /$ day for a period of 6 months. The results in these patients were compared with those obtained in the group treated initially with intravenous therapy and then with $20 \mathrm{mg} / \mathrm{kg} /$ day etidronate for 6 months. Statistical significance between differences was determined by the Student's $t$-test.

\section{Results}

\section{Effect on soft tissue swelling}

The results of etidronate therapy on soft tissue swelling are summarized in Table I. After intravenous therapy 20 patients showed a prompt reduction of swelling in the period of the first 48 hours (responders), while seven patients showed no changes or had an increase of thigh circumference (nonresponders). The mean reduction of swelling in responders was $(-) 3.4 \pm 1.4 \mathrm{~cm}$ 
Table I Reduction of soft tissue swelling after intravenous etidronate in patients with heterotopic ossification

\begin{tabular}{lccc}
\hline Group of patients & Number & Circumference difference in cm & Positive DVT \\
\hline Responders & 20 & $(-) 3.4 \pm 1.4^{\mathrm{a}}$ & 0 \\
Nonresponders & 7 & $(2.5-6)$ & 7 \\
& & $(+) 2.7 \pm 1.4^{\mathrm{b}}$ & \\
\hline
\end{tabular}

${ }^{a}$ mean $\pm \mathrm{SD}$; range indicated in parenthesis.

${ }^{\mathrm{b}} p<0.001$ vs responders.

$\mathrm{DVT}=$ deep vein thrombosis.

which was significantly lower than the initial measurement $(p<0.01)$ and also significantly different than $(+) 2.7 \pm 1.4 \mathrm{~cm}$ in the group of nonresponders $(p<0.001$; Table I). In the group of nonresponders all seven patients had ipsilateral deep vein thrombosis in the femoral or iliac vein. In addition to the quantitative changes, in the group of responders there was a considerable qualitative improvement in the degree of tissue induration, skin temperature and range of motion.

\section{Effect on ectopic ossification}

Figure 1 shows the subgroups of patients involved in the study. At the entry to the study all 27 patients had clinical and scintigraphic findings of acute $\mathrm{HO}$ but only 24 patients completed the 6 months medication protocol. The symptoms of $\mathrm{HO}$ developed $28 \pm 10$ days following SCI; scintigraphic and radiological evaluations were performed not later than 48 hours after clinical diagnosis. At the time of diagnosis patients had a mean serum alkaline phosphatase concentration of $152 \pm 91$ units (range 88-322 units/1; normal: 38-126); ESR was elevated in all patients $(65 \pm 30 \mathrm{~mm} / \mathrm{h}$; nor$\mathrm{mal}<10 \mathrm{~mm} / \mathrm{h})$. In this group, 11 patients also had positive radiographic studies, while 13 patients had no radiographic evidence of HO. In the group of 11 patients, where both scintigraphic and radiographic studies were positive, the area of ectopic bone mass was compared with the area in 12 patients treated only with oral etidronate. Figure 2 illustrates these data showing no significant differences between intravenously and

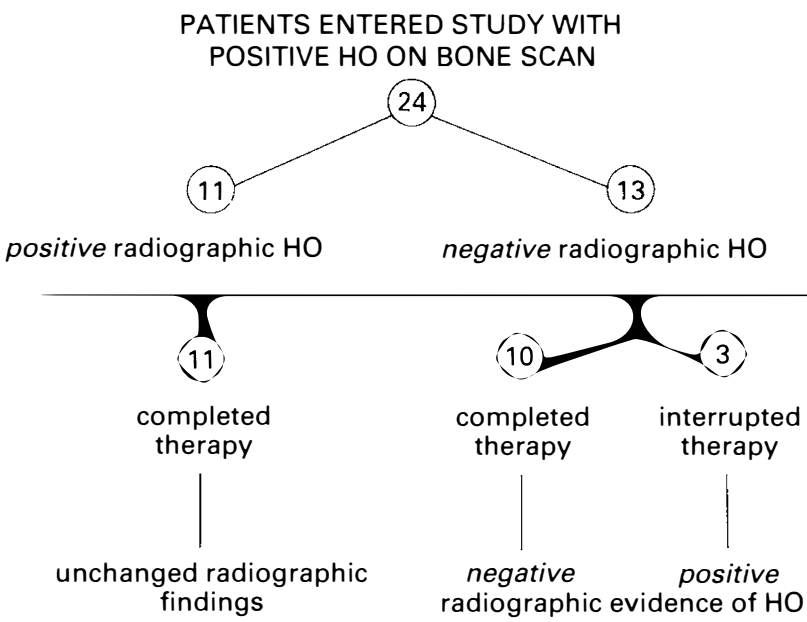

Figure 1 The subgroups of SCI patients during the treatment with Didronel. $\mathrm{HO}=$ heterotopic ossification. 
orally treated groups. Figure 3 shows the results of 13 patients with a positive bone scan and negative radiographic studies. There were two subgroups. In 10 patients with negative radiographic findings before therapy, eight showed no radiographic evidence of $\mathrm{HO}$ and two had minimal ossification after therapy (Fig 3). This group of patients were followed for a period of 6-15 months (mean 11.1 months). In the other subgroup (three patients) the medication was interrupted (in two because of surgery and in one due to noncompliance with oral medication). These patients developed ectopic ossification in the affected leg after 1-2 months.

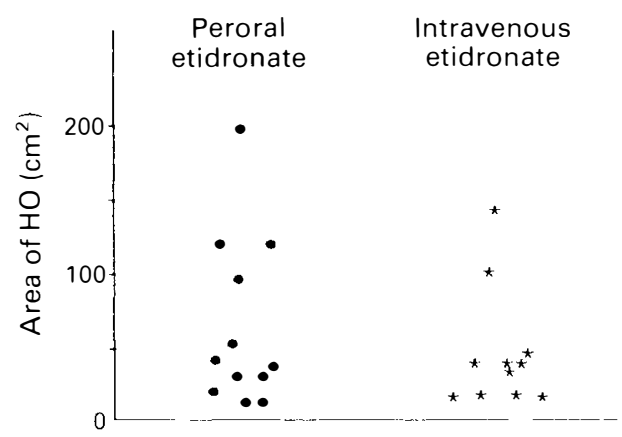

Figure 2 The mass of $\mathrm{HO}$ in SCI patients with initial radiographic evidence of HO. Area of $\mathrm{HO}$ was measured by planimetry (see 'Methods').

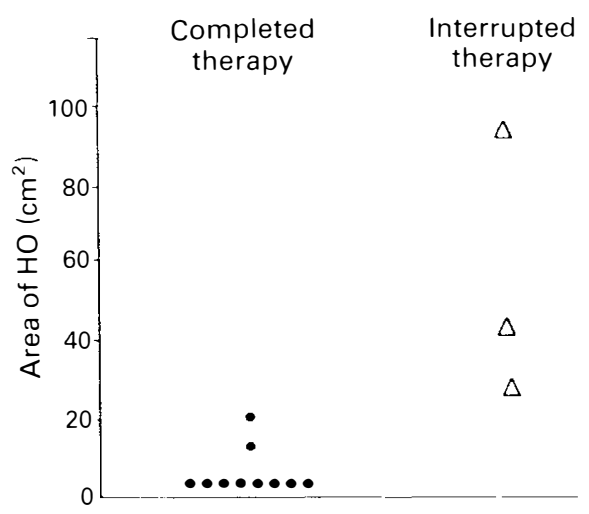

Figure 3 The mass of $\mathrm{HO}$ in SCI patients without initial radiographic evidence of $\mathrm{HO}$. Note minimal or absent $\mathrm{HO}$ in the groups that completed therapy.

\section{Discussion}

Disodium etidronate used in this study is a bisphosphonate known to have several effects on bone metabolism. ${ }^{19.20}$ This agent inhibits bone resorption through its effect on osteoclast activity. ${ }^{21.22}$ Also, etidronate can affect bone formation at the stage of mineralization, preventing the conversion of amorphous calcium phosphate to hydroxyapatite. ${ }^{22}$ The effect of etidronate on $\mathrm{HO}$ in patients with SCI has been well documented. ${ }^{4.5 .89 .18}$ Several studies have shown its efficacy on the reduction of HO development. ${ }^{4.518}$ Freed et al ${ }^{18}$ found normal radiographic findings at discharge in $31 \%$ of patients treated with etidronate. However, $69 \%$ of patients initially negative by scintigraphic criteria had various degrees of $\mathrm{HO}$ after therapy. Stover et $\mathrm{al}^{4}$ reported that etidronate therapy for 8-12 weeks reduced the prevalence of $\mathrm{HO}$ when the results were compared to placebo group. The results are even better in patients with early diagnosed HO, showing that 3 months of treatment with etidronate might decrease the prevalence of $\mathrm{HO}$ to $6 \% .5$

It is obvious from these data that etidronate has an inhibitory effect on development of HO. However, there are still a considerable number of patients who fail to respond to therapy. Several studies in animals and humans showed poor intestinal resorption of bisphosphonates. ${ }^{18}$ It is likely that physicochemical characteristics of the drug may contribute to individual differences in response to therapy. Nakahara et al ${ }^{23}$ reported that bioavailability of bisphosphonates in rats can be increased by parental administration. Furthermore, several groups found a dose dependent response in experimentally induced ectopic ossification. 23,24

On the basis of these observations we modified the therapeutic protocol and used etidronate initially by intravenous infusion followed by oral administration of $20 \mathrm{mg} /$ $\mathrm{kg} /$ day for 6 months. This oral dose of etidronate was previously suggested by Garland et al. ${ }^{8.9}$ The results obtained with such modification of present therapeutic regimen are encouraging. The patients treated early with etidronate, in whom the 
diagnosis was made by bone scan, showed no evidence of $\mathrm{HO}$ in $80 \%$ and minimal ossification in $20 \%$. The stage of $\mathrm{HO}$ development at which patients start therapy seems related to therapeutic response. In the early stages of $\mathrm{HO}$ formation, the mineralization of tissue osteoid is probably inhibited by the iv loading doses of etidronate and can be maintained in the unmineralized form with prolonged oral therapy. The effect of therapy at the late stage of $\mathrm{HO}$ formation is limited and anatomical changes becomes irreversible. In the later stages, osteoid will undergo mineralization showing radiographic signs of ectopic ossification. Although the number of our patients and time interval of follow up do not permit definitive conclusions, the results show greater therapeutic improvement than previously reported..$^{4,5}$ Using higher doses of etidronate, two important aspects require discussion; the incidence of side effects and the occurrence of $\mathrm{HO}$ after withdrawal of etidronate. Nakahara et $a^{23}$ suggested that the effect of bisphosphonates in animals is transient, because the withdrawal of the drug would cause an immediate appearance of HO. To evaluate this phenomenon further we plan to follow our patients for a longer period ( $2-3$ years) to obtain information on the long term effect of high dose of etidronate. Concerning adverse reactions, serious side effects of bisphosphonate therapy are fractures or renal complications while less significant, though more frequent, are gastrointestinal symptoms. In some of our patients there was no evidence of fractures during the period of 3 years. There are no data available on the incidence of bone fractures in SCI patients treated with bisphosphonates. In Paget's disease, Johnson $e^{a l^{25}}$ and Khari and Johnson ${ }^{6}$ were not able to find an increased incidence of fracture rate with doses of etidronate of $20 \mathrm{mg} / \mathrm{kg} /$ day even after therapy longer than 6 months. The experiments in animals confirm these clinical observations, that only three- to five-fold higher doses per body weight were associated with bone fractures. ${ }^{24}$ It seems that the fractures are more common in elderly subjects, and that younger patients better tolerate higher etidronate doses. ${ }^{26}$ Gastrointestinal symptoms (nausea and abdominal discomfort) were present in the majority of our patients but these symptoms did not require the discontinuation of therapy. Renal tests showed no abnormalities after intravenous administration of etidronate; it is likely that serious complications occur only in patients with preexisting kidney disease.

Although in this study we planned to focus primarily on the effect on ectopic ossification we found a significant effect of etidronate on soft tissue swelling. A reduction of edema and inflammatory reaction was found in all patients in the first 48 hours of intravenous therapy. This effect of etidronate has not been reported in SCI patients, but similar findings have been seen in patients with Paget's disease ${ }^{26.27}$ and in animals with experimental arthritis. ${ }^{28.29}$ The mechanism of drug action on the inflammatory process is unknown; recent data suggest that bisphosphonates may have an effect on cell-mediated immune ${ }^{12}$ and nonimmune responses..$^{30.31} \mathrm{We}$ can speculate that some cytokines locally released by inflammatory cells may play a role in the development of hyperemia and exudation. Swiss authors ${ }^{32}$ reported, using angiography and tissue histology, that prominent vasodilation and tissue edema are present in an early stage of HO. Our data support these observations and the previous findings reported in patients with Paget's disease 26.27 indicating that local humoral factors, responsible for tissue inflammation, will promptly respond to intravenous etidronate.

\section{Conclusion}

Our data indicate that in SCI patients with $\mathrm{HO}$ :

1 Intravenous etidronate in doses of 300 $\mathrm{mg} /$ day, significantly reduces soft tissue swelling associated with $\mathrm{HO}$ within the first 48 hours.

2 A therapeutic protocol using initially intravenous etidronate and then oral dose of $20 \mathrm{mg} / \mathrm{kg} /$ day for 6 months had an inhibitory effect on the development of heterotopic bone formation. These pre- 
liminary results on $\mathrm{HO}$ require further investigation in a placebo controlled fashion for better definition of optimal dosage and time period of therapy.

\section{References}

1 Liberson M (1953) Soft tissue calcification in cord lesion. JAMA 152: 1010-1014.

2 Hsu JD, Sakimura I, Stasuffear ES (1975) Heterotopic ossification around the hip joint in spinal cord injury patients. Clin Orthop 112: 165-169.

3 Wharton GW (1975) Heterotopic ossification. Clin Orthop 112: 142-149.

4 Stover SL, Hahn HR, Miller JM (1976) Disodium etidronate in the prevention of heterotopic ossification following spinal cord injury (preliminary report). Paraplegia 14: 146-156.

5 Finerman GAM, Stover SL (1981) Heterotopic ossification following hip replacement or spinal cord injury. Two clinical studies with EHDP. Metab Bone Dis 1981 3: 337-342.

6 Khari MRA, Johnston CC (1977) Treatment of Paget's disease of bone (osteitis deformans) with sodium etidronate (EHDP). Clin Orthop 127: 94-104.

7 Recker RR. Saville PD (1973) Intestinal absorption of disodium ethane-1-hydroxy-1-disphosphonate (EHDP) using a deconvolution technique. Toxicol Appl Pharmacol 24: 580-589.

8 Garland DE, Alday B, Venos KG, Vogt JC (1983) Disphosphonate treatment for heterotopic ossification in spinal cord injury patients. Clin Orthop 176: 197-200.

9 Garland DE (1990) A clinical perspective on common forms of acquired heterotopic ossification. Clin Orthop 263: 13-28.

10 Barnhart ER (1992) Physicians' Desk Reference. 46th ed. Med Econom Comp Inc. Montvale, NJ.

11 Kanis JA. Urwin GH, Gray RES, Beneton MNC. McCloskey EV, Hamdy NAT et al (1987) Effects of intravenous etidronate disodium on skeletal and calcium metabolism. Am J Med 82(2A): 55-70.

12 Garattini S, Guaitani A, Mantovani A (1987) Effect of etidronate disodium on the interactions between malignancy and bone. Am J Med 82(2A): 29-33.

13 Hasling C, Charles P, Mosekilde L (1987) Etidronate disodium in the management of malignancy-related hypercalcemia. Am J Med 82(2A): 51-54.

14 Jacobs TP, Gordon AC, Silverberg SJ, Shane E, Reich L, Clemens TL et al (1987) Neoplastic hypercalcemia: Physiologic response to intravenous etidronate disodium. Am J Med 82(2A): 42-50.

15 Meunier PJ, Chapuy MC, Delmas P. Charhon S, Edouard C, Arlot M (1987) Intravenous disodium etidronate therapy in Paget's disease of bone and hypercalcemia of malignancy: Effects on biochemical parameters and bone histomorphometry. Am J Med 82(2A): 75-78.

16 Singer FR, Fernandez M (1987) Therapy of hypercalcemia of malignancy. Am J Med 82(2A): 34-41.

17 Thiebaud D, Jaeger P, Gobelet C, Jacquet AF, Burckhard PA (1988) A single infusion of the bisphosphonate AHPrBP (APD) as treatment of Paget's disease of bone. Am J Med 85: 207-212.

18 Freed JH, Hashn H, Menter R, Dillon T (1982) The use of the three-phase bone scan in the early diagnosis of heterotopic ossification (HO) and in the evaluation of didronel therapy. Paraplegia 20: 208-216.

19 Fleisch H (1987) Bisphosphonates. In: Christiansen C, editor. Osteoporosis. International Symposium on Osteoporosis: 7-12.

20 Fleisch H (1984) Diphosphonates and osteoporosis. In: Barzel UB, editor. Osteoporosis. 11th ed. Grune \& Stration, NY: 205-222.

21 Fleisch H, Russell RGG, Francis MD (1969) Diphosphonates inhibit hydroxyapatite dissolution in vitro and bone resorption in tissue culture and in vivo. Science 165: 1262-1264.

22 Francis MD, Russell RGG, Fleisch H (1969) Diphosphonates inhibit formation of calcium phosphate crystals in vitro and pathological calcification in vivo. Science 165: 1264-1266.

23 Nakahara N, Yoshikawa H, Tokjaoka I, Ono K (1990) Effects of ethane-1-hydroxy-1, 1-diphosphosphonate on ectopic bone formation induced by murine osteosarcoma-derived bone-inducing substance. Bone 7: $229-233$

24 Flora L, Hassing GS, Cloyd GG, Bevan JA, Parfitt AM, Villanueva AR (1981) The long-term skeletal effects of EHDP in dogs. Metab Bone Dis 4/5: 289-300.

25 Johnston CC, Altma RD, Canfield RE, Fienman GAM, Taubee JD, Ebert ML (1983) Review of fracture experience during treatment of Paget's disease of bone with etidronate disodium (EHDP). Clin Orthop 172: 186-194.

26 Sadar ES, Walton RJ, Gossman HH (1972). Neurological dysfunction in Paget's disease of the vertebral column. J Neurosurg 37: 661-665.

27 Douglas DL, Kanis JA, Duckworth T, Beard DJ, Paterson AD, Russell RGG (1981) Paget's disease: Improvement of spinal cord dysfunction with disphosphonates and calcitonin. Metab Bone Dis 4/5: $327-336$.

28 Francis MD, Flora L, King WR (1972) The effects of disodium ethane -1-1-hydroxy-1, 1-diphosphonate on adjuvant induced arthritis in rats. Calcif Tiss Res 9: 109-121.

29 Flora L (1979) Comparative anti-inflammatory and bone protective effects of two diphosphonates in adjuvant arthritis. Arthritis Rheum 22: 340-346. 
30 Cecchini MC, Fleisch H (1990) Bisphosphonates in vitro specifically inhibit, among the hematopoietic series, the development of the mouse mononuclear phagocyte lineage. J Bone Min Res 5: 1019-1027.

31 Aida Y, Toda Y, Shimakoski Y, Yamada K, Anono M. Effect of disodium ethane- 1-hydroxy-1, 1-disphosphonate (DHDP) on interleukin 1 production by macrophages. Microbiol Immunol 30: 1199-1206.

32 Rossier AB, Bussat Ph, Infante F, Zanbder R, Courvoisier B, Muheaim G et al (1973) Current facts on para-osteo-arthropathy (POA). Paraplegia 11: 36-78. 